\title{
A model to reduce traffic, pollution and costs in urban distribution
}

\author{
L. F. Moreira da Silva ${ }^{1}$, O. L. Fontes Jr. ${ }^{1} \&$ D. Tacla ${ }^{2}$ \\ ${ }^{1}$ Unicamp, University of Campinas, Brazil \\ ${ }^{2}$ USP, University of São Paulo, Brazil
}

\begin{abstract}
This study aims to present a proposal to help metropolitan areas to reduce traffic, pollution and also cut delivery costs. The use of the collaborative logistics in the networking design for this fine distribution method shall allow the distribution partner to plan and execute the deliveries, reducing the number of vehicles used in comparison with the regular distribution model (this also allows the use of a clean fleet of small vehicles - like electric minivans).

The methodology used to develop the proposal is to simulate two different scenarios, comparing the variables that influence the traffic, the pollution emission and the cost involved with the distribution of goods in urban areas.

Further to the variables considered in the study, this new model needs to prove its efficiency at service level.

The conclusion of this study will compare those three variables between the regular model, where many different carriers need to reach the retail stores every day, delivering all kinds of products, with the proposed model, where only one carrier will do the deliveries in the urban areas.
\end{abstract}

Keywords: logistics, pharmaceutical logistics, pollution reduction.

\section{Introduction}

The pharmaceutical market is hardly regulated all around the world. Specifically in Brazil, this sector has increased the control of the production, handling and merchandising of this kind of products. This happened mainly after the foundation of the local Sanitary Surveillance Agency, called ANVISA.

The agency was established by the law $\mathrm{n}^{\circ}$ 9.782, from January, 1.999. Its most important characteristics is its administrative independence. 
Specifically in transportation, ANVISA establishes minimum quality standards that assure the pharmaceutical product stability, avoiding risks of injuries or reduction in its therapeutic effect for patients. Those mentioned standards increases significantly the carrier costs, once requires special licenses and permits with a high cost and investments in infrastructure additionally in comparison with transportation for other sectors.

From another standpoint, many countries around the world have increased the price control of medicines (and Brazil is not an exception on this). In the other hand, the costs are increasing faster then the medicine prices, squeezing the margins and profits of this industry and pressing them to find margin in their process, through the optimisation. Considering that the logistics costs in the pharmaceutical industry represents, alone, $3 \%$ to $8 \%$ of the medicine's final price, this has been an important source of profit increase (or recover).

At last but not at least, there is the fact that big city authorities continuously try to reduce the traffic in the city centre, one of the ways to reduce pollution.

Considering that Brazil has a really pulverized medicine retail market (we have around 55.000 pharmacies stores), which means one store for 4.000 people, while in most countries this average is around 1 store for 10.000 people - there is a huge number of really small pharmacies, obligating them to keep low inventory levels. To offset the low inventory level, those pharmacies needs to order often and the deliveries are done in a daily basis. In an average, the number of deliveries for those pharmacies is much higher than for other similar sectors (retail, p.e.). In some metropolitan areas, each store receives up to 5 deliveries per day.

This practice increases the traffic problems for those centre and deserves a special attention from those authorities that aims to reduce the pollution and traffic on those areas.

For the reason exposed here, this matter gets special interest because aims to help the industry to reduce its distribution cost and also gets reduction in the pollution and traffic rates generated by this daily flow of merchandise.

So, considering the pharmacies established in the city centre, the concept to be developed here is to try to align the reduction in the fleet used, consequently reducing the operational cost for carriers, the traffic and the pollution. The proposal is to define a lonely provider for each defined area in the city centre. This provider will need to establish a cross-dock facility nearby its area. All material designated to pharmacies in that region will be delivered in that facility. This provider will route all the deliveries for that window (that can be a time or day window), consolidate all goods to be deliver in a vehicle and proceed with the delivery.

The first benefit of this model is keep away from the city centre the traffic of medium and small trucks less than full loaded. The second benefit is that due the shortness of the routes, the provider can use smaller vehicles (like mini vans), opening this channel for the alternative fuels (electric, gas or ethanol).

A third benefit is the optimisation of the vehicles used for deliveries, allowing the carrier cut its delivery costs. 


\section{Objective}

This abstract aims to propose a new model of receiving and distributing medicines in metropolitan areas with high demographic rates, reducing costs and optimising the system as a whole. Once applied this model, expects a reduction of pollution rates and the traffic of vans, generating advantages in comparison with the current models used by the pharmaceutical market.

\section{Matter to be solved}

According recent environmental research, the global heating is a fact, although the real impacts are not fully understood. Facing this, many initiatives around the world has been taken trying to reduce the pollution generated by vehicles. One of the various alternatives to reduce the pollution is to restrict the access of vehicles to centres of big cities, enforcing the people to use mass transportation (as train or subway). However, considering everything above, other impacts are not been considered and can bring direct benefits for this aim and, additionally, can help the pharmaceutical sector to reduce its operational cost.

The question to be answered is how to join medicine logistics, accomplishment of ANVISA's regulation and vehicles flow reduction in big cities centres.

The proposal to be presented here is to generate simulations for some scenarios, considering a real flow of material from the industry to pharmacies in 2 different models. The simulation of those scenarios should show us the benefits for traffic and pollution. The criteria to analyse it is a rate that will take into consideration the following variables:

- $\quad$ Value to be loaded

- $\quad$ Volume/weight to be loaded

- $\quad$ Frequency of deliveries per monthly per zip code

The combination of those variables will determine the number of trips necessary to deliver all the material considered in the analysis and, consequently, the number of vehicles used to complete the task keeping the same service level.

\section{Methodology}

The methodology chosen to develop this paper is the simulation. Through the simulation of two different scenarios and its comparison its possible to show up the benefits of the model proposed.

To drive this study some assumptions were defined to simplify the concept development and understanding, taking it as simple as possible. Those assumptions were based on real data collected from a pharmaceutical logistics operation in São Paulo metro area. The assumptions are shown below (table 1). 
Table 1: General assumptions detailing.

\begin{tabular}{|c|c|c|c|c|}
\hline \# & Description & Value & Unit & Detail \\
\hline 1 & Average invoiced amount & 2.000 & $\mathrm{R} \$$ & Value of each invoice for each delivery for a single POS \\
\hline 2 & Average invoiced weight & 50 & $\mathrm{Kg}$ & Weight of each invoice for each delivery for a single POS \\
\hline 3 & Number of deliveries points & 1.000 & per day & Number of deliveries points reached by this study in a single day \\
\hline 4 & Number of deliveries per point a day & 2 & per day & Number of deliveries in each POS in a single day \\
\hline 5 & Unload time per point & 10 & $\min$ & Time expended in each delivery per POS \\
\hline 6 & Average distance between POS & 1 & $\mathrm{~km}$ & Distance from one POS to the next delivery \\
\hline 7 & Number of wholesalers delivering for each pharmacy & 4 & wholesalers & Usually each POS order to more than one wholesaler per day \\
\hline 8 & Van variable cost composition & $30 \%$ & Variable & Freight cost composition related to distance \\
\hline 9 & Working days & 22 & & Number of deliveries days in a month \\
\hline 10 & Currency & $\mathrm{R} \$$ & & Currency used in all calculations involving money \\
\hline
\end{tabular}

\subsection{Scenarios}

The two variables used in this study to evidence the benefits of the proposed new model are the total operational cost and the total carbonic emission of the vehicles involved in the full operation (this emission will be function of the size, kind of fuel and number of vehicles). An important matter to be consider here ignoring the kind of vehicles used is the number of vehicles involved with this operation, once the fuel kind is not necessarily linked with the distribution model, meaning that a cleaner vehicle can be used in both situation and the difference will remains to the number of vehicles used.

To facilitate the understanding of this study, it was divided into two different scenarios, the Current and the Proposed, which will be result of this paper.

\subsubsection{Current scenario}

The current scenario try to capture the situation as it is, where each pharmacy can put orders in many different wholesalers and each wholesaler makes two deliveries per day for each pharmacy. The main characteristic of this scenario is to consider the use of vans $(1,500 \mathrm{~kg}$ capacity) to collect directly in the distributor and deliver in each POS. Each van can do up to 23 deliveries in a single day, considering the time to reach the first POS (estimated at $60 \mathrm{~km}$ faraway at $60 \mathrm{~km} / \mathrm{h}$ ), the time expended for each delivery (estimated on 10 minutes) and finally the time expended to move from one POS to the next (assumed as $1 \mathrm{~km}$ at $6 \mathrm{~km} / \mathrm{h}$ ).

\subsubsection{Proposed scenario}

The proposed scenario creates a hypothetical situation where a consolidation centre will be established as closest as possible to the downtown but outside of it's restrict access border. This consolidation centre will be operated by a third party than not a wholesaler and will provide services for all the wholesalers. So, the van will not collect in each wholesaler anymore, but in the consolidation centre. In the other hand the wholesaler will not deliver directly from your distribution centre to its customers. They will be able to use bigger vehicles to collect in their distribution centre and deliver into the consolidation centre. From the consolidation centre to the final deliver, the fleet and staff involved in the operation will belong to the third party in charge of this operation. The times and 
distances involved in this scenario are exactly the same of the previous one. The unique exception is the move from the distribution centre to the consolidation centre, which will be done by truck (instead van in the current scenario).

\subsection{Values and formulas}

To proceed with the analysis proposed in this study, the following were the formulas and its development used for each scenario:

\subsubsection{Current scenario}

To define the current scenario where established some assumptions based on a real operation. Those assumptions are presented in the table 2 below. Other variables will be calculated based on those assumptions as presented in the section 4.2.1.1.

Table 2: Current scenario assumption.

\begin{tabular}{|l|l|l|}
\hline \multicolumn{1}{|c|}{ Assumption } & \multicolumn{1}{c|}{ Variable } & \multicolumn{1}{c|}{ Value } \\
\hline Number of deliveries per vehicle & Pos & \\
\hline Number of Wholesalers & Wh & 4 \\
\hline Number of deliveries per day & Dday & 2.000 \\
\hline Van Cost & Van & $\mathrm{R} \$ 300,00$ \\
\hline Distance DC to POS & Ddc & $60 \mathrm{~km}$ \\
\hline Distance between POS & Dpos & $1 \mathrm{~km}$ \\
\hline Speed DC to POS & Sdc & $60 \mathrm{~km} / \mathrm{h}$ \\
\hline Speed between POS & Spos & $6 \mathrm{~km} / \mathrm{h}$ \\
\hline Van daily cost & VanC & $\mathrm{R} \$ 300,00$ \\
\hline Van Fixed cost & Fixed & $70 \%$ \\
\hline Efficiency (loading) & Eff & $70 \%$ \\
\hline Working hours per day & $\mathrm{H}$ & $8 \mathrm{hours}$ \\
\hline Van working hours & $\mathrm{h}$ & \\
\hline
\end{tabular}

4.2.1.1 Number of vehicles involved First of all it's necessary calculate the availability of each vehicle. Considering 8 hours per day and an efficiency of $70 \%$ to do deliveries ( $30 \%$ of the time is spent in loading operation).

$$
h=H \times E f f=8 \times 70 \%=4,8 \text { hours }=4,8 \times 60=288 \mathrm{~min}
$$

Alternatively, the availability is also the sum of the time expenditure to reach the first POS and the deliver in all POS.

$$
h=T d c+T d e l
$$

Then, using the assumptions is possible to calculate the time from the DC to the first point of sales (Tdc): 


$$
T d c=\left(\frac{D d c}{S d c}\right) \times 60 \mathrm{~min}=\left(\frac{60}{60}\right) \times 60=60 \mathrm{~min}
$$

The time to do the deliveries is function of the number of point of sales to be covered:

$$
\text { Tdel }=\left(\frac{D p o s \times P o s}{S p o s}\right) \times 60 \mathrm{~min}=\left(\frac{1 \times P o s}{6}\right) \times 60=10 \times P o s
$$

Using (4) in (2) the number of point of sales covered per each vehicle should be:

$$
P o s=\frac{h-T d c}{10}=\frac{288-60}{10}=\sim 23
$$

Considering the number of deliveries per day per wholesaler, is possible to calculate the number of vehicles involved in the operation:

$$
\begin{gathered}
\text { NumberVehicles }=\left(\frac{\text { Dday } \times W h}{\text { Pos }}\right) \\
\text { Numberofvehicles }=\left(\frac{4 \times 2000}{23}\right)=348 \text { vehicles }
\end{gathered}
$$

\subsubsection{Total monthly cost}

The monthly cost of this operation is function of the number of vehicles involved, as below:

$$
\begin{gathered}
\text { Monthly } \cos t=(\text { VanC } \times \text { workdays } \times \text { numberofvehicles }) \\
\text { Monthly } \cos t=(300 \times 22 \times 348)=R \$ 2.296 .800
\end{gathered}
$$

\subsubsection{Proposed scenario}

The assumptions presented in the table 3 below were defined to the proposed scenario. Other variables will be calculated based on those assumptions as presented in the section 4.2.2.1.

4.2.2.1 Number of vehicles involved Using the formulas (1), (2), (3), (4) and (5) defined in the section 4.2.1 above, is possible calculate the number of vehicles required to run this scenario.

$$
\begin{gathered}
h=H \times \text { Eff }=8 \times 70 \%=4,8 \text { hours }=4,8 \times 60=288 \mathrm{~min} \text { and } \\
h=T d c+\text { Tdel } \\
T d c=\left(\frac{D d c}{S d c}\right) \times 60 \mathrm{~min}=0 \mathrm{~min} \\
\text { Tdel }=\left(\frac{\text { Dpos } \times \text { Pos }}{\text { Spos }}\right) \times 60 \mathrm{~min}=\left(\frac{1 \times \text { Pos }}{6}\right) \times 60=10 \times \text { Pos }
\end{gathered}
$$




$$
\begin{gathered}
\text { Pos }=\frac{h-T d c}{10}=\frac{288-0}{10}=\sim 29 \\
\text { NumberVehicles }=\left(\frac{\text { Dday } \times W h}{P o s}\right) \\
\text { Numberofvehicles }=\left(\frac{4 \times 2000}{29}\right)=276 \text { vehicles }
\end{gathered}
$$

Table 3: $\quad$ Proposed scenario assumptions.

\begin{tabular}{|l|l|l|}
\hline \multicolumn{1}{|c|}{ Assumption } & Variable & \multicolumn{1}{c|}{ Value } \\
\hline $\begin{array}{l}\text { Number of deliveries per } \\
\text { vehicle }\end{array}$ & Pos & \\
\hline Number of Wholesalers & Wh & Dday \\
\hline $\begin{array}{l}\text { Number of deliveries per } \\
\text { day }\end{array}$ & Van & 2.000 \\
\hline Van Cost & Fixed & \\
\hline Van fixed cost & Ddc & $70 \%$ \\
\hline Distance DC to POS & Dpos & $0 \mathrm{~km}$ \\
\hline Distance between POS & Sdc & $1 \mathrm{~km}$ \\
\hline Speed DC to POS & Spos & $0 \mathrm{~km} / \mathrm{h}$ \\
\hline Speed between POS & Eff & $6 \mathrm{~km} / \mathrm{h}$ \\
\hline Efficiency (loading) & H & $70 \%$ \\
\hline Working hours per day & h & $8 \mathrm{hours}$ \\
\hline Van working hours & & \\
\hline
\end{tabular}

Additionally, it's necessary to estimate the new delivery cost taking in consideration the shorter path to reach the first point of sales, according to below:

$$
\text { Van }=((\text { VanC }-(\text { VanC } \times(1-\text { Fix })) \times \text { Dcurrent })+(\text { VanC } \times(1-\text { Fix }) \times \text { Dproposed }))
$$

$$
\begin{aligned}
& \text { Dcurrent }=(D d c+(\text { Dpos } \times \text { Pos }))=(60+(1 \times 23))=83 \mathrm{~km} \\
& \text { Dproposed }=(D d c+(\text { Dpos } \times \text { Pos }))=(0+(1 \times 29))=29 \mathrm{~km}
\end{aligned}
$$

Using (8) and (9) in (7):

Van $=((300-(300 \times(1-70 \%)) \times 83)+(300 \times(1-70 \%) \times 29))=R \$ 241,00$

The proposed scenario will have additional costs related to transfer the goods from the DC to the consolidation centre and the cost to operate the consolidation centre, that involves lease and labor costs. Those costs calculation are presented in the sections 4.2.2.2, 4.2.2.3 and 4.2.2.4 below. 
4.2.2.2 Transfer truck monthly cost The assumptions presented in table 4 below are related exclusively to the truck operation added to transfer goods from the DC to the Consolidation Centre.

Table 4: $\quad$ Transfer operation assumption.

\begin{tabular}{|l|l|l|}
\hline \multicolumn{1}{|c|}{ Assumption } & \multicolumn{1}{c|}{ Variable } & Value \\
\hline Weight per day & Weight & $50 \mathrm{~kg}$ \\
\hline Average invoice weight & Winvoice & 4 \\
\hline Collection points & Collect & $\mathrm{R} \$ 400$ \\
\hline Truck Cost to & Truck & $60 \mathrm{~km}$ \\
\hline $\begin{array}{l}\text { Distance DC } \\
\text { Consolidation }\end{array}$ & Lcon & 2 \\
\hline Loads per day & Loads & 22 \\
\hline Workdays & workdays & \\
\hline Total trips per day & Trips & \\
\hline
\end{tabular}

$$
\begin{gathered}
\text { Weight }=(\text { Dday } \times \text { Winvoice })=(2.000 \times 50)=100.000 \mathrm{Kg} \\
\text { Weighttrip }=\left(\frac{\text { Weight }}{\text { Collect }}\right) \times\left(\frac{1}{\text { Loads }}\right)=\left(\frac{100.000}{4}\right) \times\left(\frac{1}{2}\right)=12.500 \mathrm{~kg}
\end{gathered}
$$

$$
\begin{gathered}
\text { Trips }=\frac{\text { Weight }}{\text { Weighttrip }}=\frac{100.000}{12.500}=8 \text { trips } \\
\text { Monthly } \cos t=(\text { Truck } \times \text { workdays } \times \text { trips }) \\
\text { Monthly } \cos t=(400 \times 22 \times 8)=R \$ 70.400
\end{gathered}
$$

4.2.2.3 Consolidation Centre monthly cost To calculate the consolidation centre cost were assumed only two assumptions regarding the size and the market price per square meter considering that the this facility will operate as a cross dock and will not keep inventory.

Table 5: Consolidation centre assumptions.

\begin{tabular}{|l|l|l|}
\hline \multicolumn{1}{|c|}{ Assumption } & \multicolumn{1}{c|}{ Variable } & \multicolumn{1}{c|}{ Value } \\
\hline Warehouse footage & $\mathrm{sqm}$ & 5.000 \\
\hline Cost per sqm & $\mathrm{R} \$ / \mathrm{sqm}$ & $\mathrm{R} \$ 12,00$ \\
\hline
\end{tabular}

$$
\text { Monthly } \cos t=(S q m \times R \$ / s q m)=(5.000 \times 12)=R \$ 60.000
$$

4.2.2.4 Labor monthly cost To the labor cost it was estimated the head count necessary to handle all the goods in and out in the facility using the local salary grade and taxes, as shown in the table 6 below: 
Table 6: Labor assumptions.

\begin{tabular}{|l|l|l|l|}
\hline \multicolumn{1}{|c|}{ Description } & \multicolumn{1}{c|}{ Quantity } & \multicolumn{1}{c|}{ Unit Wage } & \multicolumn{1}{c|}{ Cost (with tax) } \\
\hline Tax and Benefits & & & $120 \%$ \\
\hline Supervisor & 2 & 3.200 & 14.080 \\
\hline General warehouse & 8 & 650 & 11.440 \\
\hline Checkers & 4 & 950 & 8.360 \\
\hline Admin & 1 & 1.500 & 3.300 \\
\hline Other indirect cost & & & 5.000 \\
\hline Total Whs Cost & & & $\mathbf{4 2 . 1 8 0}$ \\
\hline
\end{tabular}

$$
\text { Monthly } \cos t=R \$ 42.180
$$

4.2.2.5 Van monthly cost Using the formula (6) defined in the section 4.2.1.2, the delivery cost regarding the van operation for the proposed scenario should be:

$$
\begin{gathered}
\text { Monthly } \cos t=(\text { Van } \times \text { workdays } \times \text { numberofvehicles }) \\
\text { Monthly } \cos t=(241 \times 22 \times 276)=R \$ 1.463 .352
\end{gathered}
$$

4.2.2.6 Yearly savings The yearly savings will be done by the difference between the annual cost of the current and proposed scenarios as shown below:

$$
\begin{gathered}
\text { Total } \cos t C=\text { VanCmonthly } \cos t \\
\text { Total } \cos t=\text { Van }+ \text { Truck }+ \text { Consolidationcentre }+ \text { Labor } \\
\text { Total } \cos t=1.463 .352+60.000+70.400+42.180 \\
\text { Total } \cos t=R \$ 1.635 .932 \\
\text { Savings }=(\text { Monthly } \cos \text { tcurr }- \text { Total } \cos t) \times 12 \\
\text { Savings }=(2.296 .800-1.635 .932) \times 12=R \$ 7.930 .416
\end{gathered}
$$

\section{Conclusion}

Analysing the results of the simulation of the two different scenarios can show us that the proposed model, using a consolidation centre close to the downtown, is cheaper than the current model. The cost reduction is around $29 \%$, what is a significant reduction considering to attract investments from companies to implement this model. So, even considering a third party providing the services and adding tax and profits in this cost, this model seems to be cheaper to the system.

Additionally, taking the city centre as a closed system, the model proposed involves 276 vehicles to deliver daily all the goods requested by the 1.000 pharmacies involved in this simulation. The current model should use 348 
vehicles. So, the reduction is around $21 \%$. If we consider the kind of vehicles used will be exactly the same, the pollution reduction will be approximately the same rate, $21 \%$ in that region.

Finally, the cost savings provided by this model can be partially used by the solution provider that will operate the consolidation centre to invest in cleaner vehicles, like a new and dedicated fleet of ethanol engines cars or electric cars.

To support this initiative and assure the success of this model is recommended to the big cities majors file a law to define the region where this model should be applied and also to control the quality of the fleet will be used in the fine distribution. Is recommended also a tax reduction if the company chosen uses clean vehicles to the operation, stimulating or obligating the provider to use those vehicles.

\section{References}

[1] Albrecht, Karl, 1994, Programando o Futuro (O Trem da Linha Norte), Makron Books; SP;

[2] Ballou, R.H., 1992, Business Logistics Management, 4 ed, Prentice Hall;

[3] Bowersox, D.J., Closs, D.J., 1996, Logistical Management - The Integrated Supply Chain Process, 1 ed, McGraw-Hill.

[4] Castro, C.M., 1978, A Prática da Pesquisa, 2a Edição, McGrawHill do Brasil, São Paulo.

[5] Christopher, M., 1997, Logística e Gerenciamento da Cadeia de Suprimentos - Estratégias para Redução de Custos e Melhoria dos Serviços, 1 ed. São Paulo, Editora Pioneira.

[6] Christopher, M., 2000, "The Agile Supply Chain - Competing in Volatile Markets", Industrial Marketing Management, Vol. 29, pp.37-44.

[7] Csillag, João Mario, 1995, Análise de Valor. Atlas, SP, $4^{\text {a }}$ Ed.;

[8] Mentzer, J.T., Bienstock, C., 1998, Sales Forecasting Management, 1 ed, New York, Sage.

[9] Porter, Michael, 1996, "What is Strategy?" HBR;

[10] Porter, Michael, 1980, "Competitive Strategy", New York, The Free Press;

[11] Sharman, G., 1984, "The Rediscovery of Logistics", Harvard Business Review, September/October.

[12] Harmon, Paul, 2004, "Evaluating an Organization's Business Process Maturity", Business Process Trend Newsletter, Volume2, No.3;

[13] Zinn, W., Bowersox, D., 1988, "Planning Physical Distribution with the Principle of Postponement", Journal of Business Logistics, Vol.9, No.2, pp.117-1. 